Education, Formation : le temps de l'industrialisation?

\title{
Annexe 1 - Le concept d'ingénierie de l'éducation
}

Contribution d'Yvon Minvielle - 23 mai 1992

Yvon Minvielle

\section{(2) OpenEdition}

Journals

Édition électronique

URL : http://journals.openedition.org/edc/2727

DOI : $10.4000 /$ edc. 2727

ISSN : 2101-0366

Éditeur

Université Lille-3

Édition imprimée

Date de publication : 1 mai 1993

Pagination : 73-74

ISSN : $1270-6841$

Référence électronique

Yvon Minvielle, «Annexe 1 - Le concept d'ingénierie de l'éducation », Études de communication [En

ligne], 14 | 1993, mis en ligne le 01 janvier 2012, consulté le 20 avril 2019. URL : http:// journals.openedition.org/edc/2727 ; DOI : 10.4000/edc.2727

Ce document a été généré automatiquement le 20 avril 2019

(c) Tous droits réservés 


\title{
Annexe 1 - Le concept d'ingénierie de l'éducation
}

\author{
Contribution d'Yvon Minvielle - 23 mai 1992
}

Yvon Minvielle

2 Avec la formation professionnelle, on sort de la logique de service public attachée à la formation initiale, pour accéder au secteur marchand. Tout laisse même penser qu'il faudra bien se décider à accepter que des actes de formation soient conciliables avec des activités à but lucratif. S'il est indéniable que le système associatif, ne cherchant pas à faire du profit, dispose d'une faculté non négligeable de réponse et d'adaptation aux demandes de formation, des réorganisations sont aujourd'hui nécessaires. L'évolution de l'INFREP, issu de la Ligue de l'enseignement, depuis 1981, le montre. Plus généralement, il semble possible "de faire dans le métier de la formation professionnelle ce qui a été fait dans la presse ».

3 Par ailleurs, il se trouve que la priorité accordée au contact avec l'utilisateur oblige à le reconnaître pleinement comme un acheteur, quitte à le faire bénéficier d'incitations, fiscales au besoin, si l'on veut se préserver des risques du capitalisme sauvage. Mais il est surtout urgent que, fondamentalement, la formation professionnelle se structure du point de vue économique. Sinon, comment éviter que la circulation d'argent ne reprenne le chemin de l'économie sociale et n'en reproduise les effets, en particulier pour ce qui relève de la recherche trop liée à des approches « sophistiquées » de type universitaire?

4 On peut estimer que l'absence de maturité économique, doublée sans nul doute aussi d'une immaturité des représentations sociales, explique que "les enjeux de pouvoir l'aient emporté jusqu'ici sur le jeu des projets ». Tout au plus, note-t-on l'entrée de nouveaux opérateurs, les uns venus du secteur de la communication ou du recrutement aux résultats peu probants, les autres issus d'organismes de travail temporaire proposant des formations limitées à des postes de travail identifiés.

5 Les phénomènes d'externalisation de la formation de la part des grandes entreprises, l'ouverture à la concurrence européenne, l'apparition d'un marché encore élargi par les besoins des pays sortis il 
y a encore peu de temps du communisme, constituent autant d'incitations à trouver des réponses d'une autre ampleur. La formation professionnelle doit, en particulier, se mettre en position d'avoir recours à des investisseurs financiers, y compris à l'étranger, dès que les bases juridiques seront trouvées. Il importe de dépasser le stade artisanal, et le stade du protectionnisme, si l'on espère " objectiver les actes pédagogiques et les remonter sur réseaux "; car c'est, précisément, vers une structure en réseaux, avec des enseignes, signalant des compétences reconnues dans les domaines de la formation professionnelle, qu'il faut s'attendre à voir une évolution. Mais on imagine facilement qu'il sera envisageable de toucher aussi à la pratique des bilans ou à certains domaines de la formation générale, comme l'apprentissage des langues ou de l'informatique. Une telle structure en réseaux doit permettre de répondre à une double exigence qui est de se tenir proche des besoins locaux et de s'appuyer sur des économies d'échelle suffisantes. Pouvoir « être à la fois à Béthune, et d'une taille européenne ", tel est l'enjeu. Du coup, il convient aussi d'être en mesure de formaliser les formations en termes de métiers, de les capitaliser en termes de coûts, de produits ou de prestations, et d'avancer par phases, de la création et de l'expérimentation jusqu'au lancement et à la démultiplication dans des dispositifs d'intervention appropriés. La priorité porte sur le travail des figures stratégiques fondatrices des déploiements de l'action éducative. Dans cette perspective d'industrialisation, qui passe par une authentique « $R \& D$ », la constitution d'une ingénierie s'impose. La réflexion en ingénierie éducative doit d'abord être menée au niveau des techniques et des savoir-faire mais aussi au niveau de la conduite des projets et de la maitrise d'oeuvre, comme certaines entreprises, celles du B.T.P. par exemple, qui ont à diriger des chantiers, savent déjà le faire. Enfin, puisque l'ingénierie en formation trouve sa justification ultime en ce qu'elle opère "la rencontre de la technique et du vivant ", il faut en arriver, si possible, à un niveau plus conceptuel, celui des figures et des postures de l'action humaine. Supposant au préalable " une maitrise et une production de la compétence ", l'ingénierie stimule finalement "la connaissance des processus de socialisation produisant en même temps de l'individuel et de la subjectivité ». Un vaste champ à la fois pratique et théorique est donc à constituer.

\section{AUTEUR}

\section{YVON MINVIELLE}

Yvon Minvielle, Directeur de l'INFREP 